\section{Editorial}

Check for updates

\title{
The Impact of Hospitalist Care in Korea
}

\author{
Junhwan Kim (10) \\ Department of Internal Medicine, Asan Medical Center, University of Ulsan College of Medicine, Seoul, Korea \\ - See the article "Evaluating the Outcome of Multi-morbid Patients Cared for by Hospitalists: A Report \\ of Integrated Medical Model in Korea" in volume 34, number 25, e179.
}

In 1996, Dr. Robert Wachter coined the term "hospitalist" in a New England Journal of Medicine article written with Dr. Lee Goldman. A hospitalist is a physician whose primary professional focus is the general medical care of hospitalized patients and specialized inpatient care. ${ }^{1}$ Since 1996, the number of hospitalists in the United States has increased to more than $50,000 .{ }^{2}$ The US hospitalist system reduced costs, shortened lengths of stay, and improved the quality and safety of patient care.2,3

A hospitalist system in Korea was introduced to improve the quality of patient care and to help to reduce working time of medical residents. ${ }^{4,5}$ In 2016, the Korean Health Insurance Review and Assessment Service and the Ministry of Health and Welfare started a hospitalist pilot program.

In May 2019, the number of hospitalists in Korea has increased to 124.6 Patient safety issues, resident law, and the shortage of medical residents are leading to an increase in the demand for hospitalists in Korea. However, the effect of the hospitalist system in Korea remains unproven.

Since the health care system in Korea is different from that in the US, more related studies and evidence are needed to prove the hospitalist effectiveness in Korea. In a previous study, Ohm et al. ${ }^{5}$ provided evidence that the acute care medical unit in a Korean tertiary care hospital reduces the length of stay and shortens the emergency departments waiting time. This study did not include other quality indicators, such as the morbidity, mortality, readmission rate and patient or staff satisfaction due to the short-term transit care.

In 2018, the Korean Health Insurance Review and Assessment Service and the Ministry of Health and Welfare released a hospitalist pilot program preliminary report. ${ }^{6}$ This report showed hospitalist care improves patient satisfaction, nurse satisfaction, and resident satisfaction.

In this issue of the journal, Lee et al. ${ }^{7}$ compared the outcome (including length of hospital stay [LOS], in hospital mortality [IHM], and readmission rate) in patients with pneumonia or urinary tract infection in the general wards admitted via the emergency departments between 
hospitalists and non-hospitalists. They found that the hospitalist care reduced LOS more than the non-hospitalist care, and there was no difference in overall IHM between the two groups. In particular, patients in the hospitalist group with comorbidity had shorter LOS. However, they found the readmission rates of patients in the hospitalist group were significantly increased.

This study had some limitations. First, this study was a retrospective, single center study. Second, this study lacks a logical explanation for increased readmission rates. Finally, only two hospitalists worked during the day servicing inpatient care.

Despite its limitations, this study demonstrates hospitalist care in Korea is associated with a reduced length of stay. Further studies are necessary to prove the hospitalist effectiveness in Korea.

\section{REFERENCES}

1. Pantilat S. What is a hospitalist? The Hospitalist. 2006 February;2006(2).

2. Wachter RM, Goldman L. Zero to 50,000 - The 20th anniversary of the hospitalist. N Engl J Med 2016;375(11):1009-11. PUBMED | CROSSREF

3. Lee J. Impact of hospitalist care on hospital malpractice premiums using California hospital data. Appl Econ Lett 2017;24(11):742-52. CROSSREF

4. Jang SI, Jang SY, Park EC. Trends of US hospitalist and suggestions for introduction of Korean hospitalist. Korean J Med 2015;89(1):1-5. CROSSREF

5. Ohn JH, Kim NH, Kim ES, Baek SH, Lim Y, Hur J, et al. An acute medical unit in a Korean tertiary care hospital reduces the length of stay and waiting time in the emergency department. J Korean Med Sci 2017;32(12):1917-20. PUBMED | CROSSREF

6. Kim HW. The current status of hospital medicine in Korea, 2019. Korean J Med 2019;94(2):139-44. CROSSREF

7. Lee JH, Kim AJ, Kyong TY, Jang JH, Park J, Lee JH, et al. Evaluating the outcome of multi-morbid patients cared for by hospitalists: a report of integrated medical model in Korea.J Korean Med Sci 2019;34(25):e179. CROSSREF 